\section{Patients as ethnographers}

\author{
John Launer
}

I recently spent 2 weeks as an inpatient on a hospital ward. It was not an experience I would have chosen, but I had several advantages by comparison with many of the other patients. I was ambulant for most of the time. As a doctor, I was able to understand many of the technical details of my condition and its treatment. By a strange coincidence, a colleague and friend of mine was also admitted to the same ward a few days after me, so we could support each other. As we are both involved professionally in healthcare education and organisational development, we were able to exchange our reflections on what was going on around us, including the way that the patients, nurses, doctors and other staff interacted with one another.

During one of our conversations on the ward, I came up with the playful idea that we could raise our spirits - and perhaps relieve our anxieties-by regarding ourselves not as patients but as undercover ethnographers, engaged to observe how a modern hospital ward functions. This fantasy cheered us up for the remainder of our time there. It also led us to think how patients could potentially perform a valuable role in carrying out informal ethnographic research during their time in hospital. Patients are, after all, both the recipients of care and - - in their own interests - very precise observers of this from minute to minute and day to day. What they notice around them could provide useful information about how hospitals operate in reality, and contribute to improving services.

Ethnography, by definition, is the study of cultures-in the widest sense of the word. It has its origins in observing faraway societies that were considered exotic, but nowadays is more often used to examine the language, behaviour and attitudes of groups closer to home, including doctors and healthcare workers. ${ }^{1}{ }^{2}$ Different researchers use a variety of perspectives and methods. However, they generally all share a commitment to in-depth field work within an identified group, and to writing a detailed description of their observations, along with analysis and interpretation. Their aim is sometimes to influence change in the way that the group functions. For

Correspondence to Dr John Launer, Health Education England, Stewart House, 32 Russell Square, London WC1H 5DN, UK; johnlauner@aol.com example, videoethnography - the application of ethnographic analysis to live recordings of everyday work-has been used in medical contexts to examine care in hospitals and give feedback to teams of staff on the front line. ${ }^{3}$ There are now hundreds of published ethnographic studies of patients and their experiences-as well as countless patient narratives of their own illnesses. However, there seem to be no studies done by patients from a consciously ethnographic point of view during their own hospital admissions.

\section{STRIKING OBSERVATION}

What might patient ethnographers notice on a hospital ward? During our own admissions, possibly the most striking observation my colleague and I made is how small a proportion of the day each of us spent in conversational contact with any staff member. The majority of such contacts were in fact with nursing assistants while they carried out observations of our vital signs and took ECGs, or with domestic workers who were delivering meals or cleaning and tidying. Encounters with nurses mainly centred on procedures such as inserting or removing cannulas and dispensing medication, or they were initiated by one of us while mobile and walking around the ward. Far more time was spent talking with other patients and their families. This finding surprised us, and we suspect might surprise the staff as well.

In observing the staff generally, we became interested in how different individuals performed their own roles. We noted that some staff addressed their jobs in a style that we perceived as principally procedural, while others engaged in a far more personal style. Styles seemed independent of professional identity, such as being a nurse, nursing assistant, domestic worker, pharmacist, consultant, junior doctor, medical student, porter or paramedic. They also seemed independent of people's workload, so that we saw people with identical tasks or roles addressing their work in quite different ways. Those with a mainly procedural approach carried out their assigned tasks efficiently on the whole, but in a way that appeared to avoid anything more. (A typical kind of behaviour here would be to say to a patient 'Everything fine?' and then withdraw from contact as soon as the predictably affirmative answer was given.) By contrast, those with a more personal style would engage proactively with patients, with the clear intent of listening to them, sometimes even when there was no specific task to perform. (For example, by asking 'What kind of day are you having?' when passing someone's bed, making eye contact and giving a smile, and pausing to allow time for a response).

Different staff members appeared to position themselves at various points along the spectrum, and we noted how the effects on us were also different. When staff engaged personally, we found that it enabled us to speak more fully of our lived experience of illness, including our feelings of vulnerability and fears of death, and to express emotions including sorrow. It also helped us to develop more coherent accounts of what was happening in our own bodies and our care, even if these were narratives of uncertainty, or changed with the circumstances. ${ }^{4}$ This contrasted with the effect of conversational gambits used by others that constrained us to speak only in terms of physical symptoms, or in some cases not at all. Such constraining forms of speech seemed consistent with well-known research into how professionals and organisations develop social defences to ward off their own pervasive anxiety about illness and mortality. ${ }^{5}$

\section{IMPLICATIONS FOR PATIENT SAFETY}

Our other main focus of interest was in the way staff communicated about medical care with patients, and between themselves. My colleague and I each had a few conversations with senior doctors that were detailed and unhurried. At other times, however, we were supplied with only fragmentary pieces of information about investigations and treatment by a large number of different junior doctors, including some we had never met previously. This could happen fleetingly, and at unpredictable moments. Such information sometimes included facts that we already knew, were contradictory or incorrect, were inappropriately reassuring or alarming, had been superseded by other developments, or were never acted on. While we both remained confident - as did most of our fellow patients - that our overall technical care was good, we formed the impression that there was no systematic approach to passing on information as it emerged, whether from seniors to juniors or vice versa, between professions, or to patients and their loved ones. 
We heard similar accounts from other patients and their families, and even directly from a couple of non-medical staff members. It appeared to be a significant cause of anxiety for everyone concerned. Arguably, it also had implications for patient safety. One of us spoke to the clinical lead for the unit about this. To his credit, he was receptive. It is also worth pointing out that similar problems with communication seem to be common in hospitals in England, so there may have been nothing atypical about this particular unit. $^{6}$

Our imaginary research study was brief, highly selective, and had many obvious limitations, including the fact that we were both known by almost everyone to be doctors. At the same time, I suggest that clinical units or hospitals might want to use the idea as the basis for a more formal project: namely to invite patients to keep written observations on the human activity around them, if their health permitted and they were willing to do so. Participants would need guidance on how to record these observations in a way that was descriptive rather than judgemental, and led to useful interpretation rather than complaints. Formalising such a study would also require considerable ethical and legal safeguards. Assuming these could be set up, however, our own experience indicates that patient-led ethnography could be a rich source of information for improving healthcare.

Acknowledgements I am grateful to Dr Alasdair Honeyman for his companionship on the ward and his comments on this article.

Competing interests None declared.

Provenance and peer review Commissioned; internally peer reviewed.

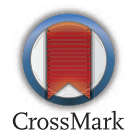

To cite Launer J. Postgrad Med J 2017;93:371-372.

Postgrad Med J 2017:93:371-372.

doi:10.1136/postgradmedj-2017-135044

(c) Article author(s) (or their employer(s) unless otherwise stated in the text of the article) 2017. All rights reserved. No commercial use is permitted unless otherwise expressly granted.

\section{REFERENCES}

1 Savage J. Ethnography and health care. BMJ 2000;321:1400-2.

2 Goodson L, Vassar M. An overview of ethnography in healthcare and medical education research. J Educ Eval Health Prof 2011;8:4

3 ledema R, Mesman J, Carroll K. Visualising Health Care Practice Improvement: Innovation from within. London: CRC Press, 2013.

4 Charon R. The patient-physician relationship. Narrative medicine: a model for empathy, reflection, profession, and trust. JAMA 2001;286:1897-902.

5 Lyth M I. Social systems as a defence against anxiety: an empirical study of the nursing service of a general hospital. Hum Sys 1960;13:95-121.

6 Ham C, Berwick D, (eds). Organising Care at the NHS Front Line: Who is responsible? London: Kings Fund, 2017. 